\title{
Direct release of embryonic sporophytes from adult Nereocystis luetkeana (Laminariales, Ochrophyta) in a high latitude estuary
}

\author{
Brian P. Ulaski* and Brenda Konar \\ College of Fisheries and Ocean Sciences, University of Alaska Fairbanks, PO Box 757220, Fairbanks, AK 99775-7220, USA
}

Kelp life history pathways alternate between macroscopic sporophytes that produce spores and microscopic gametophytes that produce gametes. Occasionally, an alternative pathway is seen. This study examined the circumstances by which the high latitude estuarine bull kelp, Nereocystis luetkeana, foregoes the "free-living microscopic stages by releasing embryonic sporophytes directly from sori. Sori were collected from adult $N$. luetkeana sporophytes from eight locations within Kachemak Bay, Alaska in 2018 and 2020 to examine spatial and temporal development of embryonic sporophytes on sori. Distinctions were made between sori collected from first-generation and overwintered adults to assess the influence of parental age on embryonic sporophyte release. Further distinctions were made between sori collected from attached and drifting individuals to assess the influence of the status of parental attachment to substrate on embryonic sporophyte release. Inspection of propagules released from sori after 48-h incubations indicated that embryonic sporophytes were occasionally released alongside viable spores. Though embryonic sporophytes were released from sori as early as spring, it was not evident that they were bound by seasonal or spatial limits. The percent of propagules that were embryonic sporophytes ranged from $0 \%$ to $100 \%$ but were not significantly different between firstgeneration and overwintered adults, nor were they different between attached and drifting individuals. Nevertheless, the characteristic of directly releasing embryonic sporophytes from adult sporophytes might have ecological advantages for N. luetkeana.

Key Words: Alaska; alternative; bull kelp; embryonic sporophytes; life history; Nereocystis luetkeana

\section{INTRODUCTION}

Kelp life histories involve a heteromorphic pattern of reproduction that alternates between two very different life stages: the sexual gametophyte stage and the asexual sporophyte stage. Conceptually, similar life histories involving an alternation between different reproductive generations are found in some fungi (Ono 2002), terrestrial plants (Fernández et al. 1999), and even animals (Jones 1937), but the technical definition of metagenesis requires separate sexual and asexual life stages, as is seen in kelps. Characteristic of kelps, the sexual gametophytes and asexual sporophytes are free-living of one another and develop independently. The macroscopic sporophytes release haploid spores from reproductive sori that contain spore-producing sporangia. Sori develop on kelp blades, with some species (e.g., Eualaria fistulosa) having specialized reproductive blades called sporophylls. Unique among some kelps (e.g., Nereocystis luetkeana) is the abscission of ripe sori from blades. Sorus abscission results from cessation of specific cells and tissue layers concurrent with forces of water motion (Amsler
(9) \$ This is an Open Access article distributed under the terms of the Creative Commons Attribution Non-Commercial License (http://creativecommons.org/licenses/by-nc/3.0/) which permits unrestricted non-commercial use, distribution, and reproduction in any medium, provided the original work is properly cited.
Received November 8, 2020, Accepted May 10, 2021

*Corresponding Author

E-mail: brianulaski@gmail.com

Tel: +1-925-519-6224, Fax: +1-907-474-5804 
and Neushul 1989). Spores start releasing from sori that are still attached to blades and continue releasing from sori after they are abscised (Walker 1980). Settled spores initiate gametogenesis and develop into dioecious gametophytes under suitable conditions. Fertilization of female gametes attached to female gametophytes produce diploid embryonic sporophytes (microscopic) that mature into adult sporophytes (macroscopic). Counter to the commonly understood timing and placement of developmental processes of microscopic stages, adult kelp sporophytes have been recently documented to release embryonic sporophytes directly from patches of sori (e.g., N. luetkeana) (Kidder 2006). Developing latter microscopic stages directly on the sorus prior to release foregoes the "free-living" component to the diplo-haplontic kelp life cycle.

Macroalgal life histories may follow annual, perennial, or biennial patterns that require persistence through changing seasons and various episodic disturbances. Though kelps are often categorized into a single life history-type, some species can have individuals within a population that fit different categories and the type of life history displayed can vary within a system (e.g., Dubois and Iken 2012, Ulaski et al. 2020). For some kelps, the biennial life history might be more common in waveprotected areas (N. luetkeana) (Springer et al. 2010). Permanency and location of the adult sporophyte results in morphological and physiological responses (e.g., Macrocystis pyrifera) (Graham et al. 2007, Buschmann et al. 2014). This morphological adaptation may be accompanied by developmental adaptations to unique environmental conditions expressed in the microscopic stages (M. pyrifera) (Kopczak et al. 1991, Ladah and ZertucheGonzalez 2007).

For many annuals, it is the variety of microscopic stages, including spores, gametophytes, and embryonic sporophytes, that appear to overwinter or survive disturbances to then restore the macroscopic population (M. pyrifera, Mann 1973; Desmarestia ligulata, Edwards 2000). Perennials can also rely on the endurance of microscopic stages through suboptimal conditions (Dayton et al. 1992). Depending on where some macroalgae grow along a vertical intertidal gradient, different microscopic stages are released as a response to immediate environmental conditions (Prasiola stipitata) (Willson 1981). Relocation of certain developmental processes (i.e., development of microscopic stages on the adult, rather than externally) may be another adaptive mechanism for kelps (N. luetkeana) (Kidder 2006). The protection that would be provided to the microscopic stage would compare to the carposporophyte stage of some red algae (Florideophycidae) as the fertilized carpogonium is not free-living of the female gametophyte (Lawson and Russell 1967). Other ecotypic adaptations include the delayed development of microscopic stages (M. pyrifera) (Kinlan et al. 2003, Carney and Edwards 2010). This may be key as to which microscopic stage operates such a function in kelps considering the susceptibility of microscopic stages to environmental stresses (Cie and Edwards 2008, Fejtek et al. 2011). If it is the haploid microscopic stages (i.e., spores or gametophytes) that arrest development and persist through stressful conditions, upon relief of the stressor they would still require successful gamete production and subsequent fertilization to repopulate the area. Since fertilization is restricted to the gametophytes being within millimeters of each other (Pterygophora californica and M. pyrifera) (Reed 1990), arrested development of the diploid microscopic stage (i.e., embryonic sporophytes) might be most beneficial to the population. If embryonic sporophytes develop on and are released directly from sori, there may be ecological advantages of propagule persistence through harsh winters, changing climate conditions, or in regions with increased grazing pressure.

Although the direct release of embryonic sporophytes from adult N. luetkeana has been observed (Kidder 2006), we know little about the spatial and temporal occurrence of their development on sori. While N. luetkeana can be either annual or biennial, it is unknown if either or both release embryonic sporophytes directly from adult sporophytes. Additionally, rafts of unattached N. luetkeana are commonly seen floating on the ocean's surface but whether they may be releasing spores or embryonic sporophytes is also unknown. As such, the present study asked two questions regarding the life history of $N$. luetkeana: (1) Are adult sporophytes directly releasing embryonic sporophytes in a high latitude estuary? and (2) Is the direct release of embryonic sporophytes a function of location, timing throughout the reproductive season, kelp age (first-generation or overwintered parents), or status of substrate attachment (attached or drifting parents)?

\section{MATERIALS AND METHODS}

\section{Study area and sample collections}

During the summers of 2018 and 2020, reproductive blades bearing sori from adult Nereocystis luetkeana 


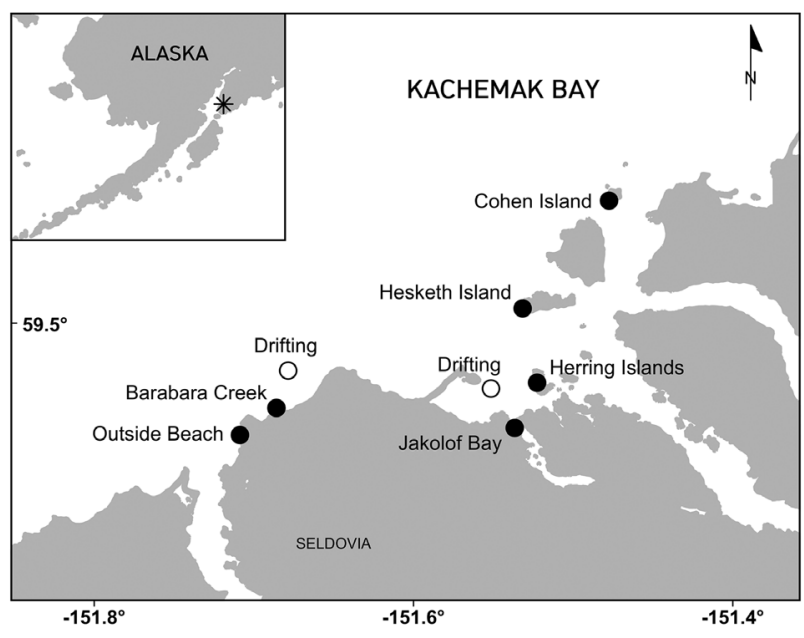

Fig. 1. Map of study area in Kachemak Bay, Alaska (black asterisk within the inset map). Sites from which Nereocystis luetkeana sori were collected are denoted by the black (collected from attached individuals) and white (collected from drifting individuals) circles. Note that drifting N. luetkeana were collected from two different locations.

(Mertens) Postels et Ruprecht sporophytes were collected from Kachemak Bay, a large high latitude estuary in Lower Cook Inlet, Alaska (Fig. 1). Collections were made by hand from a small boat. In 2018, sori were collected monthly from March to September from Outside Beach, Hesketh Island, Jakolof Bay, and the Herring Islands, which are all on the south side of the bay as this is where $N$. luetkeana is found. Sori from five to ten haphazardly selected blades of different $N$. luetkeana individuals per site per month (i.e., March through September) were tested for reproductive viability by inducing propagule release in the lab (see below; Deiman et al. 2012, Redmond et al. 2014, Traiger and Konar 2017). Direct release of embryonic sporophytes was observed during propagule release experiments in 2018 (see Results). To follow-up on these unexpected findings, sori were opportunistically collected again in August 2020 from both first-generation and overwintered individuals from Outside Beach, Barabara Creek, Cohen Island, Hesketh Island, and the Herring Islands to determine if direct release of embryonic sporophytes from sori of adult $N$. luetkeana sporophytes is determined by location or kelp age (i.e., first-generation vs. overwintered). To compare differences between attached and detached individuals, sori were also collected from drifting kelp in August 2020.

\section{Propagule release experiments}

To obtain propagules from sori, $2.5 \mathrm{~cm}$ diameter discs were removed from each ripe sorus (Traiger and Konar 2017). The sorus discs were rinsed with $0.2 \mu \mathrm{m}$-filtered seawater (filter-sterilized) and gently scraped with a razorblade to remove any macroscopic epiphytes. Sori were then wrapped in a damp paper towel and gently desiccated for one hour in a dark $10^{\circ} \mathrm{C}$ cold room to stimulate a synchronous release of propagules (Redmond et al. 2014). Each sorus was then placed in separate plastic cups filled with $100 \mathrm{~mL}$ of $10^{\circ} \mathrm{C}$ filter-sterilized seawater and a glass slide and then placed under a photoperiod of $17 \mathrm{~h}$ of light ( $50 \mu \mathrm{mol}$ photons $\mathrm{m}^{-2} \mathrm{~s}^{-1}$ fluorescent lighting) and $7 \mathrm{~h}$ of darkness (Deiman et al. 2012, Redmond et al. 2014) to mimic natural summer conditions. Microscope slides were observed under a compound microscope $(\times 400$ total magnification) for propagules after $48-\mathrm{h}$ incubations. In 2018, propagules were not quantified, individual kelps were simply recorded as either having released or not having released spores and / or embryonic sporophytes. In 2020, proportions of settled propagules were determined by ten fixed points on the ocular lens of the microscope positioned over a haphazardly selected area of the slide. The points were categorized as either "spore" or "embryonic sporophyte" depending on which propagule was nearest to each fixed point within the field of view. Propagules were only considered to be settled if they remained attached to the microscope slide after being rinsed with water.

\section{Data analysis}

Discrete data were collected on the proportions of individuals and propagules. Shapiro-Wilk tests for normality confirmed that proportions of individuals that released embryonic sporophytes and that proportions of propagules that were embryonic sporophytes were non-normally distributed (Shapiro-Wilk test, $\mathrm{p}<0.001$ ). Levene's tests confirmed that proportions of individuals and proportions of propagules were homoscedastic (Levene's test, $p>0.05$ ). A two-factor Permutational Analysis of Variance (PERMANOVA) was used to test for responses of proportions of individuals that released embryonic sporophytes to month (fixed factor) and site (random factor) from data collected in 2018. Separate one-factor PERMANOVAs were used to test for responses of proportions of propagules that were embryonic sporophytes to parental age (fixed factor), status of parental attachment to substrate (fixed factor), and location of attached individuals (random factor) from data collected in 2020. Resemblance matrices were calculated using the Euclidean distances based on a single response variable. Data 


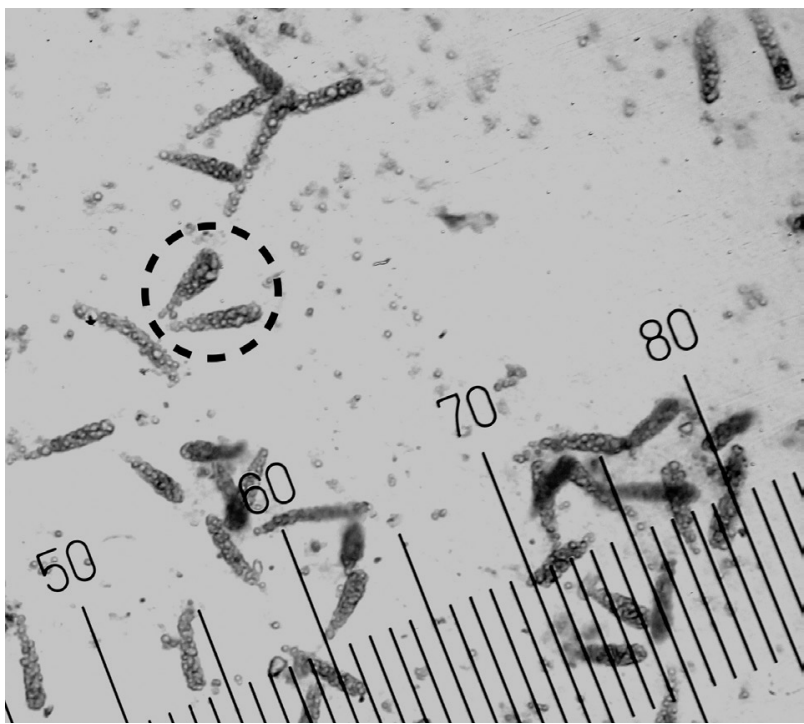

Fig. 2. Photograph of attached spores and embryonic sporophytes (within dashed circle) that were directly released from a sorus of Nereocystis luetkeana. The photograph was taken $48 \mathrm{~h}$ after initiation of propagule release. The ocular divisions are $2.5 \mu \mathrm{m}(\times 400)$.

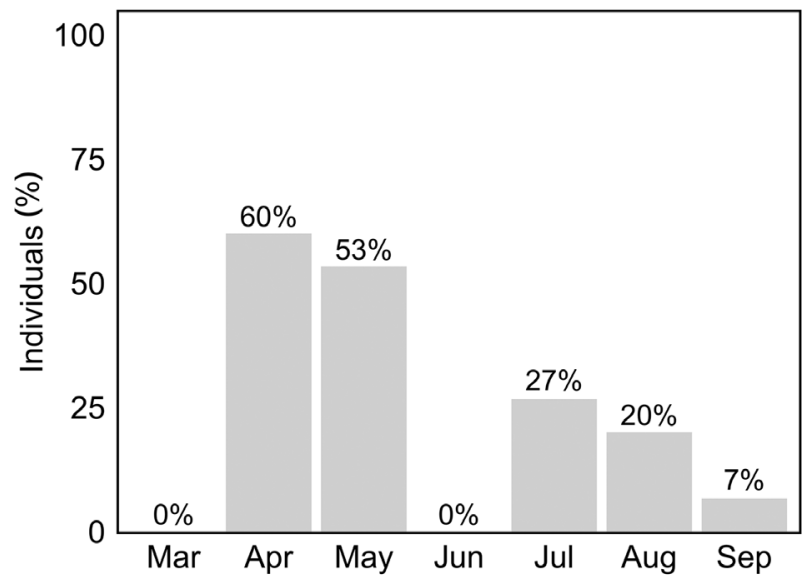

Fig. 3. Monthly proportions (\%) of all Nereocystis luetkeana individuals collected in 2018 that released embryonic sporophytes (March, $\mathrm{n}=24$ individuals; April through September, $\mathrm{n}=15$ individuals per month).

were processed in the PRIMER v7 software with the PERMANOVA+ package.

\section{RESULTS}

Embryonic sporophytes were directly released from Nereocystis luetkeana sori during the propagule release experiments in 2018 and 2020 (Fig. 2). This observation confirms the occurrence of this alternative life cycle of
N. luetkeana in a high-latitude estuarine population. Not all sori released embryonic sporophytes, but they were released from at least one sorus collected from each site (including those obtained from drift kelp). It is likely that embryonic sporophytes of $N$. luetkeana are capable of reattachment to substrate (Kidder 2006), as small, detached kelps are able to reattach if dislodged from their initial settlement (Laminaria longicruris and Laminaria digitate) (Chapman 1984). The morphological distinction that these were embryonic sporophytes was further corroborated by the multicellular structure of the microscopic thallus. In 2018, embryonic sporophytes were released as early as spring and through fall (Fig. 3). In March, the only sori available were from overwintered individuals, but the density of first-generation reproductive individuals increased as the summer progressed. By September, the only sori present were from first-generation individuals. Propagules released from sori collected in March $(n=24)$ and June $(n=15)$ did not contain embryonic sporophytes. Overall, there was a general decrease over time in the proportion of individuals that released embryonic sporophytes. The highest proportion of individuals within a given month that released embryonic sporophytes was in April $(60 \%, \mathrm{n}=15)$, with the lowest proportion in September $(7 \%, \mathrm{n}=15)$. During the months in which adult $N$. luetkeana released embryonic sporophytes, the proportions of individuals that did were similar over time (PERMANOVA, $p=0.2$ ). Although there was an overall decrease in the proportions of individuals that released embryonic sporophytes over time, when averaged by site, the mean proportions were similar across seasons. When averaged by month, the proportions of individuals that released embryonic sporophytes were also similar among sites (PERMANOVA, $p=0.4$ ). Spatially, the direct release of embryonic sporophytes was not explained by location within Kachemak Bay. Interaction effects of month and site could not be tested as only single monthly proportions were recorded for each site in 2018; thus, there was no replication at the level of month-site interaction.

Sori were collected from an assortment of first-generation and overwintered adults in 2018, but the categorical distinction of parental age was not associated with each sorus during collection. However, the distinction of whether collected sori came from first-generation or overwintered adults was made during the August 2020 collections (Fig. 4A). These additional propagule release experiments revealed that the proportions of propagules that were embryonic sporophytes were similar between first-generation $(n=30)$ and overwintered $(n=29)$ re- 

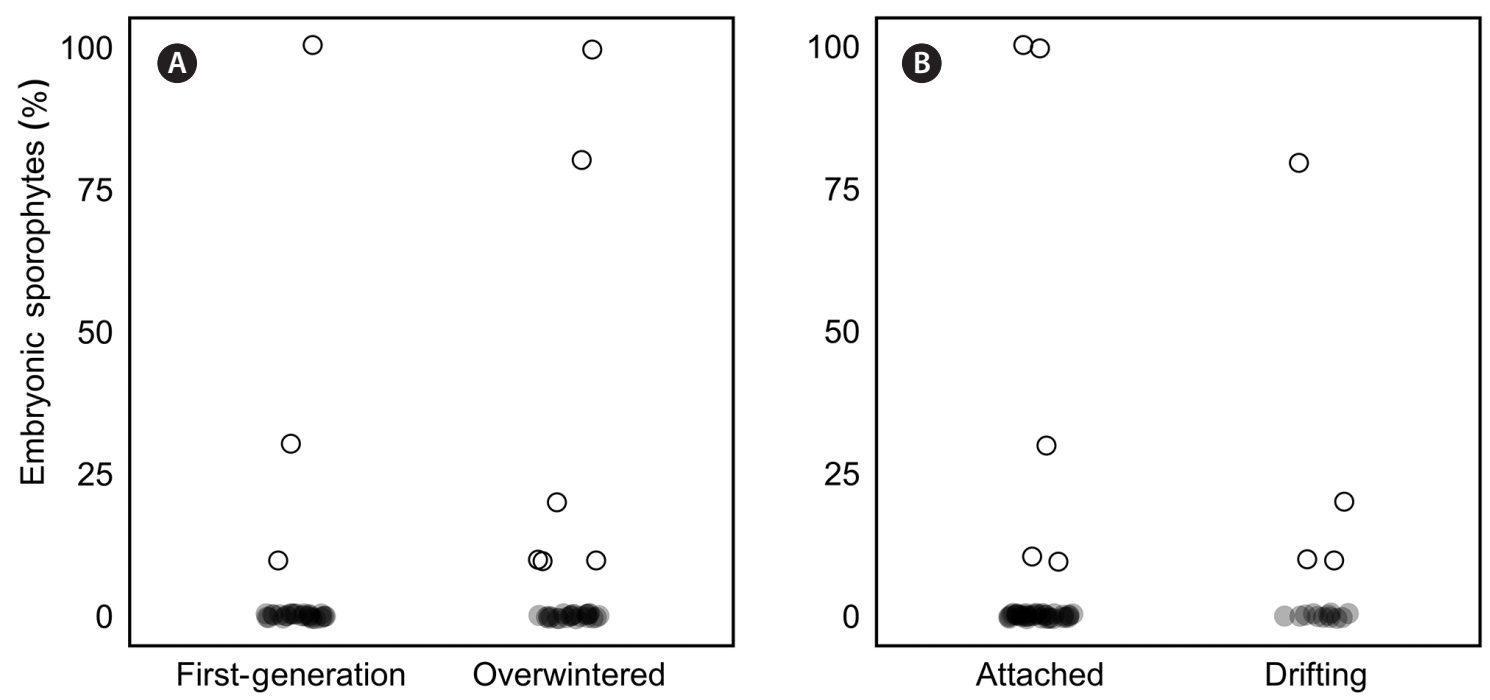

Fig. 4. Proportions (\%) of settled propagules released from Nereocystis luetkeana sori in August 2020 that were embryonic sporophytes. Data are faceted by first-generation versus overwintered adults (A) and attached versus drifting adults (B). Each circle represents an individual sorus. White circles denote possible outliers (beyond 1.5 times the interquartile range).

productive individuals (PERMANOVA, $\mathrm{p}=0.7$ ). In 2020, the distinction was also made of whether collected sori came from adults that were still attached to the substrate and from detached adults that were drifting on the surface of the water column (Fig. 4B). The proportions of propagules that were embryonic sporophytes were also similar between attached $(\mathrm{n}=44)$ and drifting $(\mathrm{n}=16)$ reproductive individuals (PERMANOVA, $\mathrm{p}=0.7$ ). For both categorical distinctions of parental age and status of parental attachment to substrate, the proportions of propagules that were embryonic sporophytes were mostly $0 \%$, with only a few individuals releasing higher percentages of embryonic sporophytes between $10 \%$ and $100 \%$. Few individuals released embryonic sporophytes overall, with similar proportions released among sites (PERMANOVA, $\mathrm{p}=0.1$.

\section{DISCUSSION}

While direct release of embryonic sporophytes from adult bull kelp, Nereocystis luetkeana, has been documented in lower latitudes (Kidder 2006), further efforts were made here to identify the circumstances by which this seemingly uncommon alternate life history occurs. We observed the direct release of embryonic sporophytes from both first-generation and overwintered N. luetkeana in a high latitude estuary. $N$. luetkeana can display a biennial life history in which overwintered individu- als are capable of contributing to the reproductive pool (Chenelot 2003). Not only do overwintered individuals release viable spores, but they also occasionally release embryonic sporophytes directly from sori. Kelp age (firstgeneration versus overwintered adults) and whether or not the parent is attached to the substrate did not explain differences in the proportions of released propagules that are embryonic sporophytes. Though there was no significant variability over time in the proportion of individuals that released embryonic sporophytes, some reproductive adults directly contribute this latter microscopic stage as early as March. The spatial scale investigated herein did not reveal any significant variability in foregoing the freeliving microscopic stages among $N$. luetkeana throughout the study region. Some individuals were collected from kelp beds situated near islands within the bay that are more oceanic influenced, while some were slightly more sheltered. Given the counterclockwise circulation of water throughout the bay (Johnson 2021), some beds were situated in more freshwater influenced embayments. However, proximity to freshwater discharge did not explain the occurrence of embryonic sporophyte development on sori. A more rigorous investigation of environmental variability over larger spatial scales across geographically separated populations may reveal differences in the development and release of embryonic sporophytes from $N$. luetkeana.

The development of embryonic sporophytes on adult sporophytes might have evolutionary or ecotypic ad- 
vantages. It has been suggested that this new strategy is advantageous against grazing and other disturbances (Kidder 2006). Though embryonic sporophytes are not necessarily more resistant to grazing or sedimentation, their vertical location within the water column may offer a spatial refuge. By retaining a developing microscopic stage on blades at the surface of the water column before sorus abscission, herbivory may be reduced due to currents and wave action being greater at the surface with generally fewer surface and water column herbivores than benthic ones. Sedimentation also negatively affects $N$. luetkeana microscopic stages (Deiman et al. 2012, Traiger and Konar 2018). With the development of embryonic sporophytes at the surface, sediment scour and shading effects are only temporarily reduced. Effects of sedimentation would resume once the embryonic sporophytes are released to then settle and grow on the seafloor. Releasing embryonic sporophytes can, however, allow for more rapid development once they settle, giving them a competitive advantage as suggested by Carney and Edwards (2010), provided they are not inhibited by conditions of low light and low nitrate concentrations (Deysher and Dean 1986). Much of Alaska has high wave action (no sites in this study were classified as protected) and grazing pressure is common (Chenelot and Konar 2007, Dubois and Iken 2012). This alternate life cycle may also be advantageous for future populations if grazing pressure increases, as a function of warming waters, as it has in other regions of the world (Provost et al. 2017). Since embryonic sporophytes are capable of having ecotypic adaptations under unique conditions, this may be why they develop on blades of first-generation and overwintered adults in a high latitude estuary with extreme winters (seasonally limited light) and sediment input from its numerous watersheds. Those that develop on blades might support higher rates of recruitment success and persistence through winter and early spring. If they develop late in the growing season and are retained on the blades through winter, they may be less light limited at the surface with short daylengths. If they are released in spring, rapid development would occur early in the growing season before the new generation appears. This may help explain continuous rather than seasonally pulsed recruitment events.

Macroalgae that are detached from the substrate may tangle with other individuals and marine debris to form drifting rafts on the ocean's surface as a means of dispersal (Waters et al. 2018). This may be an important mechanism for dispersal over great distances as drifting kelps may remain reproductively functional (Macaya et al. 2005). Drifting kelps releasing embryonic sporophytes may be beneficial in terms of dispersal into a new area as processes of spore germination, development of gametophytes, and subsequent fertilization would already be accomplished prior to release from the raft.

Though there are advantages of this alternate life history strategy, limitations and lack of evidence from elsewhere might be indicative of negative population effects. $N$. luetkeana is distinctive in releasing its sorus from blades on the ocean surface that sink to the seafloor before sporangia dehisce and release spores. By developing embryonic sporophytes directly on the sorus, it is possible that their development is a result of self-fertilization. Costs associated with self-fertilization in kelps include loss of fitness and depression of competitiveness (Raimondi et al. 2004). Parthenogenesis is another possible mechanism by which embryonic sporophytes develop from female gametophytes or spores that do not undergo meiosis on the sorus, also likely to have disadvantageous effects of lowering genetic diversity or irregular development (Gall et al. 1996).

The present study corroborates previous work that suggests an alternate life history strategy for N. luetkeana involving the direct release of embryonic sporophytes from sori of reproductive adult sporophytes. However, this study was observational and more rigorous genetic and spatial investigations are needed to deduce potential patterns and consequences of this occurrence. Further experimental work could reveal if the release of embryonic sporophytes occurs throughout its distribution, if this phenomenon is density-dependent, or if it is facilitated by certain environmental events. There may also be other alternate pathways in addition to the one described herein. Without further investigation, it cannot be discounted that parthenogenetic embryonic sporophytes might develop from individual sporangia. It is also possible that similar alternate pathways in other kelps have gone undocumented thus far.

\section{ACKNOWLEDGEMENTS}

We thank K. Iken for providing feedback on the manuscript. We are also thankful to S. Lindstrom for providing insight on kelp life history. Thank you to the National Oceanic and Atmospheric Administration/University of Alaska Fairbanks Kasitsna Bay Laboratory for field support. The research was sponsored by Alaska Sea Grant, University of Alaska Fairbanks (project R/101-12), with funds from the National Oceanic and Atmospheric Ad- 
ministration (grant NA18OAR4170078), and from the University of Alaska with funds appropriated by the state of Alaska. Additional support was provided by the Northern Gulf of Alaska Applied Research Award and the Robert and Kathleen Byrd Award.

\section{CONFLICTS OF INTEREST}

The authors declare that they have no potential conflicts of interest.

\section{REFERENCES}

Amsler, C. D. \& Neushul, M. 1989. Diel periodicity of spore release from the kelp Nereocystis luetkeana (Mertens) Postels et Ruprecht. J. Exp. Mar. Biol. Ecol. 134:117-127.

Buschmann, A. H., Pereda, S. V., Varela, D. A., RodríguezMaulén, J., López, A., González-Carvajal, L., Schilling, M., Henríquez-Tejo, E. A. \& Hernández-González, M. C. 2014. Ecophysiological plasticity of annual populations of giant kelp (Macrocystis pyrifera) in a seasonally variable coastal environment in the Northern Patagonian Inner Seas of Southern Chile. J. Appl. Phycol. 26:837-847.

Carney, L. T. \& Edwards, M. S. 2010. Role of nutrient fluctuations and delayed development in gametophyte reproduction by Macrocystis pyrifera (Phaeophyceae) in southern California. J. Phycol. 46:987-996.

Chapman, A. R. O. 1984. Reproduction, recruitment and mortality in two species of Laminaria in southwest Nova Scotia. J. Exp. Mar. Biol. Ecol. 78:99-109.

Chenelot, H. 2003. Factors affecting estuarine populations of Nereocystis luetkeana in Kachemak Bay, Alaska. M.S. thesis, University of Alaska Fairbanks, Fairbanks, AK, USA, 89 pp.

Chenelot, H. \& Konar, B. 2007. Lacuna vincta (Mollusca, Neotaenioglossa) herbivory on juvenile and adult Nereocystis luetkeana (Heterokontophyta, Laminariales). Hydrobiologia 583:107-118.

Cie, D. K. \& Edwards, M. S. 2008. The effects of high irradiance on the settlement competency and viability of kelp zoospores. J. Phycol. 44:495-500.

Dayton, P. K., Tegner, M. J., Parnell, P. E. \& Edwards, P. B. 1992. Temporal and spatial patterns of disturbance and recovery in a kelp forest community. Ecol. Monogr. 62:421-445.

Deiman, M., Iken, K. \& Konar, B. 2012. Susceptibility of Nereocystis luetkeana (Laminariales, Ochrophyta) and Eualaria fistulosa (Laminariales, Ochrophyta) spores to sedimentation. Algae 27:115-123.

Deysher, L. E. \& Dean, T. A. 1986. Interactive effects of light and temperature on sporophyte production in the giant kelp Macrocystis pyrifera. Mar. Biol. 93:17-20.

Dubois, A. \& Iken, K. 2012. Seasonal variation in kelp phlorotannins in relation to grazer abundance and environmental variables in the Alaskan sublittoral zone. Algae 27:9-19.

Edwards, M. S. 2000. The role of alternate life-history stages of a marine macroalga: a seed bank analogue? Ecology 81:2404-2415.

Fejtek, S. M., Edwards, M. S. \& Kim, K. Y. 2011. Elk kelp, Pelagophycus porra, distribution limited due to susceptibility of microscopic stages to high light. J. Exp. Mar. Biol. Ecol. 396:194-201.

Fernández, H., Bertrand, A. M. \& Sánchez-Tamés, R. 1999. Biological and nutritional aspects involved in fern multiplication. Plant Cell Tissue Organ Cult. 56:211-214.

Gall, E. A. (Gall, Y. L.), Asensi, A., Marie, D. \& Kloareg, B. 1996. Parthenogenesis and apospory in the Laminariales: a flow cytometry analysis. Eur. J. Phycol. 31:369-380.

Graham, M. H., Vásquez, J. A. \& Buschmann, A. H. 2007. Global ecology of the giant kelp Macrocystis: from ecotypes to ecosystems. Oceanogr. Mar. Biol. Annu. Rev. 45:39-88.

Johnson, M. A. 2021. Subtidal surface circulation in lower Cook Inlet and Kachemak Bay, Alaska. Reg. Stud. Mar. Sci. 41:101609.

Jones, R. W. 1937. Alternation of generations as expressed in plants and animals. Bios 8:19-29.

Kidder, K. A. 2006. Ecology and life history of Nereocystis luetkeana in the South Slough estuary. M.S. thesis, University of Oregon, Eugene, OR, USA, 101 pp.

Kinlan, B. P., Graham, M. H., Sala, E. \& Dayton, P. K. 2003. Arrested development of giant kelp (Macrocystis pyrifera, Phaeophyceae) embryonic sporophytes: a mechanism for delayed recruitment in perennial kelps? J. Phycol. 39:47-57.

Kopczak, C. D., Zimmerman, R. C. \& Kremer, J. N. 1991. Variation in nitrogen physiology and growth among geographically isolated populations of the giant kelp, Macrocystis pyrifera (Phaeophyta). J. Phycol. 27:149-158.

Ladah, L. B. \& Zertuche-González, J. A. 2007. Survival of microscopic stages of a perennial kelp (Macrocystis pyrifera) from the center and the southern extreme of its range in the Northern Hemisphere after exposure to simulated El Niño stress. Mar. Biol. 152:677-686.

Lawson, R. P. \& Russell, G. 1967. Simultaneous occurrence of carposporophytes and tetrasporangia in Polysiphonia urceolata. Br. Phycol. Bull. 3:249-250. 
Macaya, E. C., Boltaña, S., Hinojosa, I. A., Macchiavello, J. E., Valdivia, N. A., Vásquez, N. R., Buschmann, A. H., Vásquez, J. A., Vega, J. M. A. \& Thiel, M. 2005. Presence of sporophylls in floating kelp rafts of Macrocystis spp. (Phaeophyceae) along the Chilean Pacific coast. J. Phycol. 41:913-922.

Mann, K. H. 1973. Seaweeds: their productivity and strategy for growth. Science 182:975-981.

Ono, Y. 2002. Life cycle and nuclear behavior in three rust fungi (Uredinales). Mycoscience 43:37-45.

Provost, E. J., Kelaher, B. P., Dworjanyn, S. A., Russell, B. D., Connell, S. D., Ghedini, G., Gillanders, B. M., Figueira, W. \& Coleman, M. A. 2017. Climate-driven disparities among ecological interactions threaten kelp forest persistence. Glob. Change Biol. 23:353-361.

Raimondi, P. T., Reed, D. C., Gaylord, B. \&Washburn, L. 2004. Effects of self-fertilization in the giant kelp, Macrocystis pyrifera. Ecology 85:3267-3276.

Redmond, S., Green, L., Yarish, C., Kim, J. \& Neefus, C. 2014. New England seaweed culture handbook: nursery systems. Connecticut Sea Grant, Groton, CT, 92 pp.

Reed, D. C. 1990. The effects of variable settlement and early competition on patterns of kelp recruitment. Ecology 71:776-787.

Springer, Y. P., Hays, C. G., Carr, M. H. \& Mackey, M. R. 2010.
Toward ecosystem-based management of marine macroalgae: the bull kelp, Nereocystis luetkeana. Oceanogr. Mar. Biol. Annu. Rev. 48:1-42.

Traiger, S. B. \& Konar, B. 2017. Supply and survival: glacial melt imposes limitations at the kelp microscopic life stage. Bot. Mar. 60:603-617.

Traiger, S. B. \& Konar, B. 2018. Mature and developing kelp bed community composition in a glacial estuary. J. Exp. Mar. Biol. Ecol. 501:26-35.

Ulaski, B. P., Konar, B. \& Otis, E. O. 2020. Seaweed reproduction and harvest rebound in Southcentral Alaska: implications for wild stock management. Estuar. Coasts 43:2046-2062.

Walker, D. C. 1980. Sorus abscission from laminae of Nereocystis luetkeana (Mert.) Post. and Rupr. Ph.D. dissertation, University of British Columbia, Vancouver, British Columbia, Canada, $487 \mathrm{pp}$.

Waters, J. M., King, T. M., Fraser, C. I. \& Craw, D. 2018. Crossing the front: contrasting storm-forced dispersal dynamics revealed by biological, geological and genetic analysis of beach-cast kelp. J. R. Soc. Interface 15:20180046.

Willson, M. F. 1981. On the evolution of complex life cycles in plants: A review and an ecological perspective. Ann. Missouri Bot. Gard. 68:275-300. 